\title{
Effect of adenoidectomy / tonsillectomy on temporomandibular joint (TMJ) function and mouth opening in early period
}

\author{
Adenoidektomi ve/veya tonsillektomi ameliyatının erken dönemde \\ temporomandibular eklem (TME) ve ağız açıklığına olan etkisi
}

\author{
Celal GÜNAY ${ }^{1}$, Raşit CEVizCi ${ }^{1}$, Ahmet KELEŞ ${ }^{1}$, Alper DilLCi ${ }^{2}$, Yıldırım BAYAZIT ${ }^{1}$
}

\section{ABSTRACT}

The aim of this study was to investigate the effects of mouth gag used in adenoidectomy / tonsillectomy on temporomandibular joint (TMJ) function and mouth opening with using digital dial type caliper. Mouth opening distance and TMJ function of a total of 50 patients including 30 patients (6-43 yrs, 17 men, and 13 women) who had undergone adenoidectomy / tonsillectomy and 20 patients (19-47 yrs, 12 men and 8 women) of the control group who had undergone septoplasty between November 2015 and November 2016 at ENT Department of tertiary medical center were measured using digital dial type caliper one hour before, and one week, and one month after the operation. Changes in the distance of mouth opening at $4^{\text {th }}$ hour, 1 week and 1 month postoperatively in the adenoidectomy / tonsillectomy group were statistically significant $(p=0.001, p<0.01)$. Changes in the distance of mouth opening at $4^{\text {th }}$ hour, 1 week and 1 month postoperatively in the septoplasty group were not statistically significant $(p>0.05)$. There is $57.5 \%$ positive correlation between patients' age, and range of mouth opening in two groups ( $r: 0.575, p=0.001, p<0.01)$. As a conclusion; mouth opening and TMJ function might be effected by mouth gag in adenoidectomy / tonsillectomy surgeries depending on the duration of surgery and age of the patient. Small sample size and short follow-up period were limitations of the study.

Keywords: Adenotonsillectomy, temporomandibular joint, mouth opening, mouth gag
Öz

Bu çalışmada, adenoidektomi ve/veya tonsillektomi yapılan hastalarda ameliyat sırasında kullanılan ağız ekartörüne bağlı olarak ağız açıklığı derecesinde ve temporomandibular eklemde (TME) etkilenme olup olmadığının dijital kumpas aleti kullanılarak değerlendirilmesi amaçlandı. Kasım 2015 - Kasım 2016 yılları arasında üçüncü basamak bir KBB kliniği tarafından ağız ekartörü kullanılarak adenoidektomi ve/veya tonsillektomi ameliyatı yapılan 30 hasta (6-43 yaşları arası, 17'si erkek ve 13'ü kadın) ile, kontrol grubu olarak septoplasti ameliyatı olan 20 hasta (1947 yaşları arası, 12'si erkek ve 8'i kadın ) olmak üzere toplam 50 hastanın ağız çene açıklığı dijital kumpas aleti ile ameliyattan 1 saat önce, 4 saat sonra, 1 hafta sonra ve 1 ay sonra olmak üzere ölçüldü. Adenoidektomi ve/veya tonsillektomi yapılan hastalarda operasyon sonrası 4. saat, 1 hafta sonrası ve 1 ay sonrası ağız açıklığı ölçümlerindeki değişim istatistiksel olarak anlamlı bulunmuştur ( $p=0,001, p<0,01)$. Septoplasti yapılan hastalarda ise operasyon sonrası 4.saat, 1.hafta sonrası ve 1 ay sonrası ağız açıklığı ölçümlerindeki değişim istatistiksel olarak anlamlı bulunmamıştır ( $p>0,05)$. Her iki gruptaki ağız açıklığı ölçümlerinin yaş ile ilişkisine bakıldığında; yaşla beraber ağız açıklığındaki artışın da \%57,5 düzeyinde korelasyon gösterdiği saptanmıştır ( $r: 0,575, p=0,001$, $p<0,01)$. Sonuç olarak, adenoidektomi ve/veya tonsillektomi gibi ağız ekartörü kullanılarak yapılan ameliyatlarda; ağız açıklığı ve TME fonksiyonu ameliyat süresi ve hastanın yaşına bağlı olarak etkilenebilmektedir. Ancak, örneklem sayısının küçük ve takip süresinin kısa olması çalışmanın kısıtlılıklarıdır.

Anahtar kelimeler: Adenotonsillektomi, temporomandibular eklem, ağız açıklığı, ağız ekartörü
GiRiş

Rekürren adenoid ve tonsil enfeksiyonları, uyku apnesi, semptomatik hale gelmiş adenotonsiller hipert- rofi, halitozis, peritonsiller apse, malignite şüphesi, rekürren otitis media, PFAPA sendromu gibi birçok nedenden dolayı adenoidektomi ve/veya tonsillektomi ameliyatı yapılmakta ve bu ameliyat dünyada en

Received: 01.01.2017

Accepted: 09.02.2017

${ }^{1}$ Istanbul Medipol University, Department of Otorhinolaryngology, Istanbul, Turkey

${ }^{2}$ Eskisehir Yunus Emre State Hospital, Department of Otorhinolaryngology, Eskisehir, Turkey

Yazışma adresi: Alper Dilci, Eskisehir Yunus Emre State Hospital, Department of Otorhinolaryngology, Eskisehir, Turkey

e-mail: alperdilci@yahoo.com 
çok gerçekleştirilen cerrahilerin başında gelmektedir $^{1}$. Postoperatif dönemde anestezi komplikasyonlarının yanında, boğaz ağrısı, ses değişikliği, nazone konuşma, tat değişiklikleri, kanama ve ağız ekartörüne bağlı olarak diş ve çene ekleminde komplikasyonlarla karşılaşılabilmektedir ${ }^{1,2}$. Postoperatif ağrı postoperatif komplikasyonlar içerisinde en sık karşılaşılan olmakla beraber, sıklıkla yapılan cerrahiye bağlı olmanın dışında uzun süreli veya aşırı ağız ekartasyonuna bağlı TME travmasından da kaynaklanabilmektedir ${ }^{3}$.

TME dış kulak yolunun hemen önünde yer almaktadır; temel olarak rotasyon ve translasyon hareketleri olan diartrodial bir eklemdir ${ }^{4}$. TME'in istirahat pozisyonu; ağzın hafif aralıkken dudakların kapalı olduğu, dişlerin tam olarak birbirine temas etmediği, dilin ise ön parçasının sert damağa temas ettiği pozisyondur. Muskuler veya artiküler kaynaklı çeşitli nedenler TME'de ağrı ve hasara yol açabilmektedir ${ }^{5,6}$.

TME hastalıklarında görülen başlıca bulgular; eklemde klik sesi ve krepitasyon, çenede hareket kısıtıılığı ve trismus, eklemde ve çevresinde ağrı, aurikulotemporal sinire bağlı olarak işitme kaybı, tinnitus ve vertigo gibi otolojik semptomlardır ${ }^{6,7}$. TME'e bağlı hastalıklar rutin klinik pratiğimizde sıklıkla karşılaşılmakta ve genellikle göz ardı edilmektedir. TME hastalıkları sıklıkla travmaya bağlı olmakla beraber, başlıca 25-45 yaş arası kadınlarda görülmektedir ${ }^{8}$.

Adenoidektomi ve/veya tonsillektomi gibi ameliyatlarda yapılan ağız ekartasyonuna bağlı olarak TME hiperekstansiyonu ve TME travması ile karşılaşılabilmektedir ${ }^{8}$. Bu çalışmanın amacı, adenoidektomi ve/ veya tonsillektomi gibi ağız ekartörü kullanılarak yapılan ameliyatların TME eklem fonkisyonuna ve buna bağı ılarak ağız açıklığına olan etkilerini araştırmaktır.

\section{GEREÇ ve YÖNTEM}

Çalışmaya Kasım 2015 - Kasım 2016 tarihleri arasında Medipol Üniversitesi Hastanesi KBB Kliniğinde adenoidektomi ve/veya tonsillektomi ameliyatı yapılan 30 hasta ile kontrol grubu olarak septoplasti ameliyatı yapılan 20 hasta dahil edilmiştir. Çalışmanın Etik Kurul Onayı Yerel Etik Kurulundan alınmış olup, çalışmaya katılan tüm hastalar çalışma hakkında bilgilendirilmiş ve aydınlatılmış onam alınmıştır. TME disfonksiyonu olanlar, öncesinde ağız içi cerrahi müdahale geçirenler, konnektif doku hastalığı olanlar, ortodontik hastalığı olan bu nedenle ameliyat edilmiş olan hastalarla ameliyat süresi 1 saati aşan hastalar çalışmaya dahil edilmedi. TME disfonksiyonu olan hastaların tespiti ve çalışma dışı bırakılmasında örneklemin oluşturulmasında TME disfonskiyonu sorgulama formu kullanıldı ${ }^{9}$.

Çalışmaya dahil edilen tüm hastaların ameliyatları tek bir doktor tarafından yapıldı. TME travması ve ağız açıklığının değerlendirilmesi için yapılan ağız açıklığı ölçümü yine tek bir doktor tarafından dijital kumpas aleti kullanılarak ameliyattan 1 saat önce, ameliyattan 4 saat sonra, 1 hafta sonra ve 1 ay sonra olmak üzere ölçüldü. Ağız açıklığı ölçümleri 0,01 hata payı olan $15,0 \mathrm{~cm}$ uzunluğunda dijital kumpas aleti kullanılarak yapıldı. Ağız açıklığı, ağzın maksimum açılabildiği konumda alt ve üst çene kesici dişlerin serbest yüzeyleri arasındaki mesafenin ölçümüyle bulundu. Bu mesafe ÖKDAMM olarak tanımlandı ve her hasta için 2 defa ölçüldü ve bu ölçümlerden büyük olanı kaydedildi. Ölçümler ameliyattan 1 saat önce, ameliyat sonrası 4. saat, ameliyat sonrası 1 hafta ve 1 ay olarak aynı doktor tarafından yapıldı. Anestezi açısından standardizasyon sağlanması için tek bir anestezi hekimi tarafından aynı protokol kullanıldı; ameliyatlar da tek bir hekim tarafından aynı cerrahi prensipler gözetilerek yapıldı. Ameliyat süresi 1 saati aşan vakalar uzun süreli ekartasyonun etkisinden dolayı çalışma dışı tutuldu. Adenoidektomi ve/veya tonsillektomi ameliyatı sırasında yeterli ekspojuru sağlamak için hastaya uygun büyüklükte Boyle-Davis ağız açacağı (Aesculap OM 114R, OM 119R) kullanıldı.

\section{İstatistiksel Metot}

İstatistiksel analizler için NCSS (Number Cruncher Statistical System, 2007, Kaysville, Utah, USA) programı kullanıldı. Çalışma verileri değerlendirilirken ortalama, standart sapma, standart hata, medyan, fre- 
kans, yüzde, minimum, maksimum kullanıldı. Grup ve zamanın ağız açıklığı değerleri üzerine olan etkilerini incelemek amacıyla üç faktörlü yinelemeli ölçümler varyans analizi gerçekleştirildi. Analize grup ve zaman bağımsız değişken, yaş kovaryat olarak, ağzı açıklığı miktarı ise bağımlı değişken olarak dahil edildi. i̇ki bağımsız grup arası değerlendirmelerde t test kullanıldı. Normal dağılım göstermeyen değişkenlerin iki grup arası karşılaştırmalarında ise Mann-Whitney $U$ test kullanıldı. Nicel değişkenler arasındaki ilişki düzeyinin belirlenmesinde Spearman korelasyon analizi kullanıldı. Anlamlılık $p \leq 0,05$ düzeylerinde değerlendirildi.

\section{BULGULAR}

Çalışmaya dahil edilen hasta grubu, yaşları 6 ile 43 arasında değişen 17'i erkek (\%56) ve 13'ü kadın (\%44) olmak üzere 30 hastadan ve kontrol grubu ise yaşları 18 ile 47 arasında değişen 12 'si erkek (\%60) ve 8'i kadın (\%40) 20 hastadan oluşmaktadır (Tablo 1).
Adenoidektomi ve/veya tonsillektomi grubunda ameliyattan 1 saat önceki ağız açıklığı ölçümlerine göre; ameliyat sonrası 4 . saat, 1 hafta sonrası ve 1 ay sonrası ağız açıklığı ölçümlerindeki değişim istatistiksel olarak anlamlı düzeyde yüksek bulunmuştur $(p=0,001, p<0,01)$.

Septoplasti grubunda ameliyattan 1 saat önceki ağız açıklığı ölçümlerine göre; ameliyat sonrası 4. saat, 1 hafta sonrası ve 1 ay sonrası ağız açıklığı ölçümleri arasında istatistiksel olarak anlamlı ilişki saptanmamıştır $(p>0,05)$ (Tablo 2).

Adenoidektomi/tonsillektomi ameliyatı olan ve septoplasti ameliyatı olan hastalarda ağız açıklığı ölçümlerinin yaş ile ilişkisine de bakılmıştır. Ağız açıklığı ölçümleriyle yaş faktörünün arasında pozitif korelasyon gösteren $\% 57,5$ oranında istatistiksel olarak anlamlı bir ilişki saptanmıştır ( $r: 0,575, p=0,001, p<0,01)$ (Tablo 3).

Tablo 1. Çalışmaya dahil edilen hasta ve kontrol grubunun sosyodemografik özellikleri.

\begin{tabular}{|c|c|c|c|}
\hline Çalışmanın sosyodemografik özellikleri & Adenoidektomi/Tonsillektomi $(n=30)$ & Septoplasti $(n=20)$ & $\mathbf{p}$ \\
\hline Cinsiyet, n (\%) & $\begin{array}{l}\text { Erkek: } 17(\% 56,7) \\
\text { Kadın: } 13(\% 43,3)\end{array}$ & $\begin{array}{l}\text { Erkek: } 12(\% 60,0) \\
\text { Kadın: } 8(\% 40,0)\end{array}$ & ${ }^{\mathrm{a}} 0,815$ \\
\hline Yaş (yıl) & $\begin{array}{l}\text { Min-Mak (medyan): 6-43 (7.5) } \\
\text { Ort } \pm \text { ss: } 11,00 \pm 8,96\end{array}$ & $\begin{array}{l}\text { Min-Mak (medyan): } 18-52 \text { (33.5) } \\
\text { Ort } \pm \text { ss: } 32,75 \pm 10,04\end{array}$ & ${ }^{\mathrm{b}}<0,001^{* *}$ \\
\hline
\end{tabular}

${ }^{a}$ Pearson ki-kare test, ${ }^{b}$ Mann Whitney $\cup$ test, ${ }^{* *} p<0.01$

Tablo 2. Adenoidektomi / tonsillektomi ameliyatı ve septoplasti ameliyatı olan hastaların ağız açıklığı ölçümlerinin analizi.

\begin{tabular}{|c|c|c|c|}
\hline Ağız açıklığı ölçümleri & $\begin{array}{l}\text { Adenoidektomi/Tonsillektomi }(\mathrm{n}=30) \\
\text { Min-Mak (Medyan) Ort } \pm \text { Ss }\end{array}$ & $\begin{array}{l}\text { Septoplasti ( } n=20) \\
\text { Min-Mak (Medyan) Ort } \pm \text { Ss }\end{array}$ & p \\
\hline Operasyondan 1 saat önce & $\begin{array}{l}31-52,8(41) \\
40,86 \pm 5,41\end{array}$ & $\begin{array}{l}36,4-56,2(47,5) \\
47,19 \pm 6,56\end{array}$ & $0,002 * *$ \\
\hline Operasyon sonrası 4. saat & $\begin{array}{l}27,5-50,1(38,2) \\
38,85 \pm 5,53\end{array}$ & $\begin{array}{l}36,7-55,2(45,5) \\
46,10 \pm 6,05\end{array}$ & $0,001 * *$ \\
\hline Operasyon sonrası 1 . hafta & $\begin{array}{l}29,3-50,8(38,2) \\
39,17 \pm 5,51\end{array}$ & $\begin{array}{l}36,3-55(46,4) \\
46,58 \pm 6,19\end{array}$ & $0,001 * *$ \\
\hline Operasyon sonrası 1 . ay & $\begin{array}{l}30,9-51,7(39,7) \\
40,34 \pm 5,36\end{array}$ & $\begin{array}{l}37-56,6(47,2) \\
47,59 \pm 6,51\end{array}$ & $0,001 * *$ \\
\hline 1 saat önce -4 . saat (\%) & $\begin{array}{l}-6,3-14,6(5) \\
4,97 \pm 3,81\end{array}$ & $\begin{array}{l}-2,4-7(1,8) \\
2,18 \pm 2,20\end{array}$ & $0,001 * *$ \\
\hline 1 saat önce - 1 . hafta (\%) & $\begin{array}{l}-3,1-20,5(3,5) \\
4,13 \pm 4,09\end{array}$ & $\begin{array}{l}-2,8-5,4(0,6) \\
1,19 \pm 2,23\end{array}$ & $0,002 * *$ \\
\hline 1 saat önce -1 . ay (\%) & $\begin{array}{l}-8,3-14,2(1) \\
1,22 \pm 3,29\end{array}$ & $\begin{array}{l}-4,7-2,2(-0,5) \\
-0,89 \pm 1,67\end{array}$ & $0,001^{* *}$ \\
\hline
\end{tabular}

p:Mann Whitney $U$ Test, ${ }^{*} p<0,05,{ }^{*} p<0,01$ 
Tablo 3. Hasta ve kontrol grubuna göre ağız açıklığı ölçümlerinin yaş faktörü ile ilişkisi.

\begin{tabular}{|c|c|c|c|}
\hline Ağız açıklığı ölçümleri & & \multicolumn{2}{|c|}{ Yaş } \\
\hline Operasyondan 1 saat önce & $\mathrm{p}$ & $0,001 * *$ & 0,779 \\
\hline \multirow[t]{2}{*}{ Operasyon sonrası 4. saat } & $r$ & 0,584 & 0,103 \\
\hline & $p$ & $0,001 * *$ & 0,667 \\
\hline Operasyon sonrası 1 . hafta & $r$ & 0,600 & 0,129 \\
\hline \multirow[t]{2}{*}{ Operasyon sonrası 1. ay } & $r$ & 0,593 & 0,130 \\
\hline & $\mathrm{p}$ & $0,001 * *$ & 0,584 \\
\hline \multirow[t]{2}{*}{1 saat önce - 4. saat (\%) } & ${ }^{\mathrm{r}} \mathrm{r}$ & $-0,216$ & $-0,293$ \\
\hline & $p$ & 0,251 & 0,209 \\
\hline \multirow[t]{2}{*}{1 saat önce -1 . hafta (\%) } & ${ }^{\dagger} r$ & $-0,121$ & $-0,242$ \\
\hline & $\mathrm{p}$ & 0,251 & 0,303 \\
\hline
\end{tabular}

r:Pearson Korelasyon Katsayısı, 'r:Spearman's Korelasyon Katsayısı

\section{TARTIŞMA}

Ağız ekartörü kullanılan ameliyatlarda TME travmasına bağlı olarak ağrı, trismus ve çene ekleminde hareket kısıtlılığı gibi sorunlarla karşılaşılabilir. Adenoidektomi ve/veya tonsillektomi dünyada en sık yapılan cerrahilerden biridir ve ağız ekartörünün kullanılması bu komplikasyonların da klinik pratikte sıklıkla karşılaşılmasına yol açmaktadır ${ }^{4}$. Adenoidektomi ve/veya tonsillektomi ameliyatı sonrasında görülebilen ağız açıklığındaki azalmanın başlıca nedenleri peritonsiller yapılardaki cerrahi travma, tonsillektomi kavitesinin, yumuşak damak ve çevre yumuşak dokuların postoperatif fibroz iyileşmesi olarak sıralanabilir³. Ağız açıklığındaki azalmanın diğer bir nedeni de ağız ekartörünün TME'i gereğinden fazla zorlamasıyla aşırı ekstansiyona bağlı eklem yapısı üzerinde hasara neden olması da olabilir ${ }^{3,6}$. Literatür incelendiğinde tonsillektomi sonrası ağız açıklığının azalması tonsiller yatağın fibröz iyileşmesi ve TME'in fibröz ankilozuna bağlanmıştır ${ }^{10}$. Bu ameliyatlar sırasında TME dislokasyonu ile de karşılaşılabilmektedir. Gupta ve ark.'nın ${ }^{11}$ bildirmiş olduğu olgu sunumunda post tonsillektomi döneminde trismus ve ciddi eklem ağrısı olan hastada mandibula kondil fraktürü tespit edilmiştir.

TME hastalıklarının semptomları çok fazla değişken- lik göstermektedir. Hem rutin klinik pratikte hem de postoperatif dönemdeki hastalarda kolaylıkla gözden kaçmaktadır. Travma, TME hastalıklarının başlıca nedenidir ve TME disfonksiyonu olan hastaların yaklaşık yarısında travma öyküsüyle karşılaşııır ${ }^{12}$. Travma sonrası eklemde ilk olarak travmatik artrit ve efüzyon oluşur. Travma sonrası akut bulgular 1-2 gün içinde rezolüsyona uğrayabilir fakat eklem içerisinde kanama, fibrozis, eklem içi adezyonlar ya da hiperplazi oluşumu ile de karşılaşılabilir. Bu fizyolojik süreçler hastanın TME bölgesinde ciddi ağrı hissetmesine ve hareket kısıtlılığı ile karşılaşmasına yol açabilir ${ }^{13}$. Ön kesici dişler arası maksimum mesafe (ÖKDAMM) sağlıklı bireylerde 23-71 mm arası değişmekte ve TME kondil mobilitesinden etkilenmektedir ${ }^{14}$. Çalışmamızda, adenoidektomi ve/veya tonsillektomi grubunda ameliyat sonrası ilk ÖKDAMM ortalama ölçümlerinde düşüş görülmüştür. Postoperatif izlem sırasında 4. haftada ÖKDAMM ortalama ölçümlerinde bir yükseliş görülmüş, ancak ilk ölçümlerdeki ortalama değerlere ulaşılamamıştır. Cerrahiye bağlı yaklaşık 20 gün kadar süren postoperatif ağrı erken dönemde ağız açıklığının azalmasına yol açabilir, ancak 4 haftalık ölçümlerdeki azlık, ağız ekartasyonuna bağlı olası TME hasarını işaret edebilir.

Literatürde Maini ve ark.'nın ${ }^{10}$ yapmış olduğu tek kör prospektif kontrollü çalışmada, adenoidektomi 
ve/veya tonsillektomi yapılmış olan hastaların ağız açıklık miktarları değerlendirilmiş; 4 haftalık izlemde hasta grubunda kontrol grubuna göre istatistiksel olarak anlamlı bir azalma tespit edilmiştir. Diğer bir çift kör çalışmada ise ameliyat sonrası ağız açıkIığını değerlendirmek için daha uzun bir takip süresi gözetilmiş sonuç olarak ağız açıklığı değerlerinin normalleştiği görülmüştür ${ }^{15}$. Bu çalışmada ise, 4 haftalık takip süresi sonrasında ağız açıklığı değerlerinin adenoidektomi ve/veya tonsillektomi yapılan grupta anlamlı olarak azalmış olduğu gösterilirken, kontrol grubunda herhangi bir değişiklik gösterilememiştir. Uzun takip sürelerinin gözetildiği çalışmalarda ağzı açıklığı değerlerinin normalleştiği tespit edilse de, adenoidektomi ve/veya tonsillektominin olasılıkla ağız ekartasyonuna bağlı olarak TME fonksiyonuna ve ağız açıklığı üzerine olan olumsuz etkisi mevcuttur. Kundi ve ark. ${ }^{16}$ çalışmamıza benzer olarak tonsillektomi sonrası erken dönemde TME fonksiyonunda bozulma olduğunu göstermiş ve buna bağlı olarak trismus ve TME ağrısı gözlemlemiştir. Ağız ekartasyonu süresinin kısa tutulmasıyla postop erken dönemde bu bulguların önüne geçilebileceği önerilmiştir.

Bu çalışmanın en büyük kısıtlılıklarından biri; ağız ekartörünün ne kadar açıldığının ve TME'i ne kadar zorladığının objektif olarak saptanamamasıdır. Ayrıca, TME fonksiyonun ağız açıklığı dışında değerlendirilmesinin subjektif olması da diğer bir dezavantajdır. Literatürdeki bu tür çalışmalardaki en büyük kısıtlılıklardan birisi de ağız ekartörünün ağız içerisinde farklı sürelerde kalıyor oluşudur. Bu nedenle bu çalışmada, ameliyat süresinin 1 saat olarak sınırlandırılması bu kısıtlılığın önüne geçtiğini düşünmekteyiz. Bu sürenin altında ve üzerinde biten ameliyatlardaki hastaların çalışma dışı bırakılmış olması ameliyat süresi değişkeninin ekarte edilmesini sağlamıştır. Çalışmamızda, postoperatif erken dönemde ÖKDAMM değerleri düşmüş, 4 hafta sonrasında değerlerde bir artış görülmeye başlanmış, ancak sonuç olarak ilk değerlere erişilememiştir. Yeni yapılacak çalışmalarda, takip süreleri uzatılarak ÖKDAMM değerlerindeki değişim hakkında daha net bilgi sahibi olunabilir.
Sonuç olarak, daha büyük örneklemin, daha uzun takip sürelerinin olduğu, radyolojik ölçümlerle intraoperatif ÖKDAMM ölçümlerinin yapıldığı objektif yeni çalışma modelleri oluşturulabilirse bu konu hakkında anlamlı ve yeni bilgilere ulaşılabilecek ve bu tip ameliyatların TME'i etkileme durumu daha sağlıklı değerlendirilebilecektir. Daha uzun takip sürelerinin olduğu çalışmalar planlandığında; bu tür cerrahilerin ağız açıklığı ve TME fonksiyonu üzerine olan uzun dönemdeki etkileri daha net anlaşılması ve kalıcı sekel bırakıp bırakmadığının tespiti açısından değerli bilgiler elde edilebilir.

\section{KAYNAKLAR}

1. Shinhar S, Scotch BM, Belenky W, et al. Harmonic scalpel tonsillectomy versus hot electrocautery and cold dissection: an objective comparison. Ear Nose Throat J 2004;83:712-715.

2. Guida RA, Sorvino DW, Sobol SM. Tonsillectomy and adenoidectomy. In: Essentials of Otolaryngology. Lucente FE, Sobol SM (eds). $3^{\text {rd }}$ edition. Philadelphia: Lippincott-Raven, 1997:355-361.

3. OkesonJP. Orofacialpain:Guidelinesforassessment, diagnosis, and management. Chicago, Quintessence Publishing Co Inc, 1996.

4. Rayne J, Phil D. Functional anatomy of the temporomandibular joint. British Journal of Oral and Maxillofacial Surgery 1987;25:92-99. https://doi.org/10.1016/0266-4356(87)90002-7

5. Magee DJ. Temporomandibular Joint. Orthopedic Physical Assessment. $4^{\text {th }}$ edition. Philadelphia: Saunders, 1997:183206.

6. Yalçın S, Aktaş i. Temporomandibular eklem hastalıkları. In: Diş Hekimliğinde Temporomandibular Eklem Hastalarına Yaklaşım. Yalçın S, Aktaş i (eds). İstanbul: Vestiyer Yayın Grubu, 2010: 24-25.

7. Adlam DM. Temporomandibular Pain Syndrome. In: Rheumatology. Klippel JH, Dieppe PA (eds). 2nd edition. London: Mosby International Lynton House, 1998: 4.13.1-13.6.

8. Aksoy C. Temporomandibular eklem hastalıkları ve ağrı. In: Baş, Boyun ve Bel Ağrıları. Siva A, Hancı M (eds). İstanbul: KayaBasım, 2002:109-117.

9. Aktaş i. Temporomandibular Eklem Redüksiyonsuz Disk Deplasmanı Hastalıklarında Uygulanan Farklı Tedavilerin Klinik ve MRG Bulgularıyla Değerlendirilmesi. İstanbul Üniversitesi Sağlık Bilimleri Enstitüsü Ağız Diş Çene Hastalıkları ve Cerrahisi Anabilim Dalı, Doktora tezi, İstanbul, 2008.

10. Maini S, Osborne JE, Fadl HMS, et al. Temporomandibular joint dysfunction following tonsillectomy. Clin Otolaryngol Allied Sci 2002;27:57-60. https://doi.org/10.1046/j.0307-7772.2001.00528.x

11. Gupta SC, Singh SR, Misra T, Misra VP. Fracture of the mandibular condyle as a complication of tonsillectomy. Ear Nose Throat J 1989;68:477-479.

12. Greco CM,Rudy TE,Turk DC, et al. Traumatic onset of temporomandibular disorders: positive effects of astandardized conservative treatment program. Clin J Pain 1997;13:337347. 
https://doi.org/10.1097/00002508-199712000-00012

13. Yengin E. Temporomandibular rahatsızlıklarda teşhis ve tedavi. İstanbul: Dilek Matbaacılık; 2000.

14. Sönmez H, Sarı S, Oksak GO, Çamdeviren H. Prevalence of temporomandibular dysfunction in Turkish children with mixed and permanent dentition. Journal of Oral Rehabilitation 2001;28:280-285. https://doi.org/10.1111/j.1365-2842.2001.tb01700.x

15. Hydri AS, Malik SM. Reduced mouth opening following tonsillectomy in children: myth or reality. J Coll Physicians Surg Pak 2010;20:781-784.

16. Kundi NA, Mehmood T, Abid O. Application of mouth gag and temporomandibular joint pain and trismus in tonsillectomy. $J$ Coll Physicians Surg Pak 2015;25:268-270. 